Provided for non-commercial research and education use. Not for reproduction, distribution or commercial use.

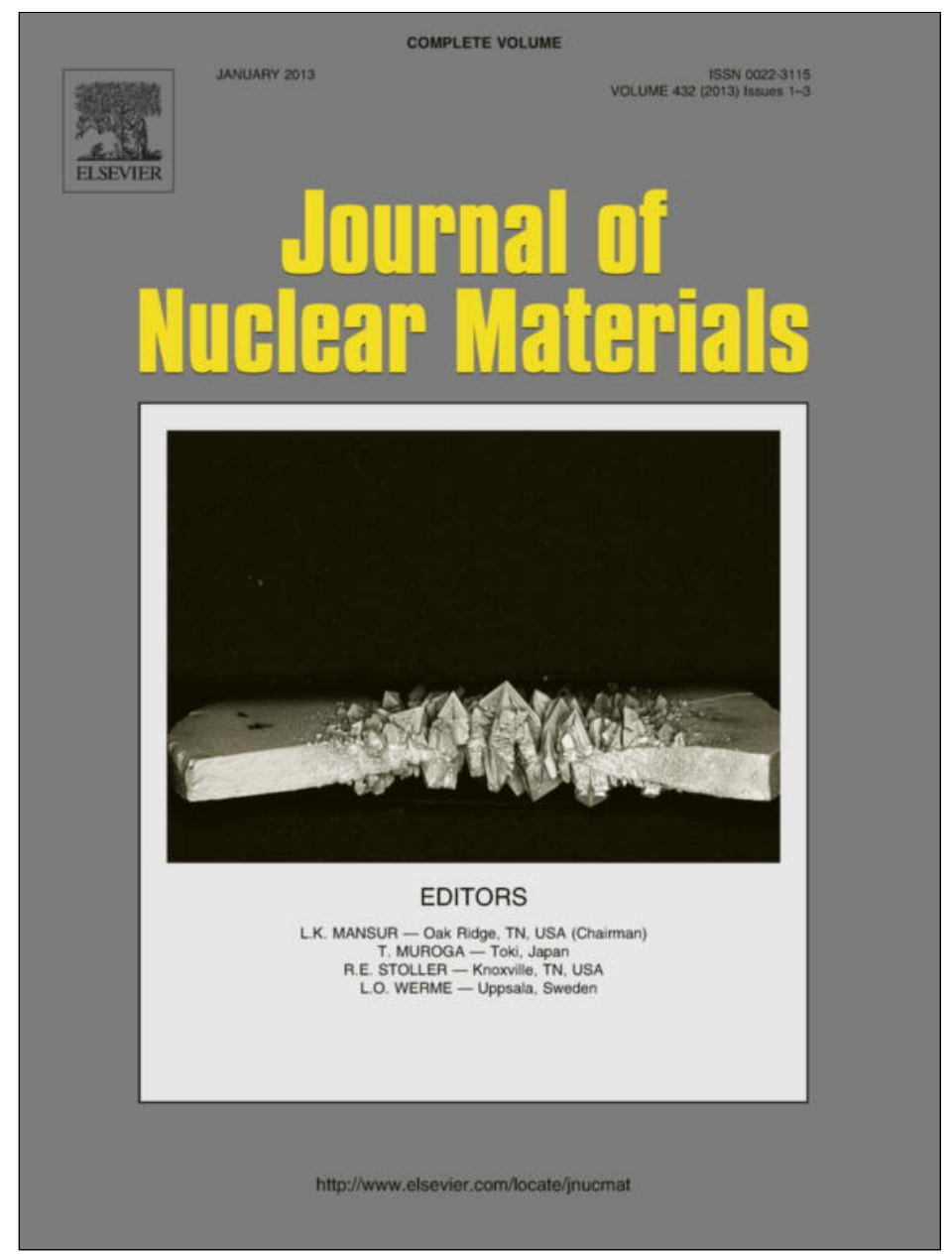

This article appeared in a journal published by Elsevier. The attached copy is furnished to the author for internal non-commercial research and education use, including for instruction at the authors institution and sharing with colleagues.

Other uses, including reproduction and distribution, or selling or licensing copies, or posting to personal, institutional or third party websites are prohibited.

In most cases authors are permitted to post their version of the article (e.g. in Word or Tex form) to their personal website or institutional repository. Authors requiring further information regarding Elsevier's archiving and manuscript policies are encouraged to visit:

http://www.elsevier.com/copyright 


\title{
The chemical durability of glass and graphite-glass composite doped with cesium oxide
}

\author{
Nasir H. Hamodi ${ }^{\mathrm{a}, *}$, Timothy J. Abram ${ }^{\mathrm{a}}$, Tristan Lowe ${ }^{\mathrm{b}}$, Robert J. Cernik ${ }^{\mathrm{b}}$, Eddie López-Honorato ${ }^{\mathrm{c}}$ \\ ${ }^{a}$ School of Mechanical, Aerospace and Civil Engineering (MACE)/University of Manchester, Pariser Building, F-floor, Manchester M13 9PL, UK \\ ${ }^{\mathrm{b}}$ Henry Mosley Imaging Facility, Material Science Centre, University of Manchester, Manchester M13 9PL, UK

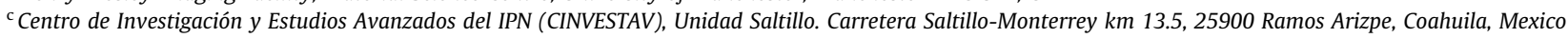

\section{A R T I C L E I N F O}

\section{Article history:}

Received 8 May 2012

Accepted 5 September 2012

Available online 13 September 2012

\begin{abstract}
A B S T R A C T
The role of temperature in determining the chemical stability of a waste form, as well as its leach rate, is very complex. This is because the dissolution kinetics is dependent both on temperature and possibility of different rate-controlling mechanisms that appear at different temperature regions. The chemical durability of Alumina-Borosilicate Glass (ABG) and Glass-Graphite Composite (GGC), bearing Tristructural Isotropic (TRISO) fuel particles impregnated with cesium oxide, were compared using a static leach test. The purpose of this study is to examine the chemical durability of glass-graphite composite to encapsulate coated fuel particles, and as a possible alternative for recycling of irradiated graphite. The test was based on the ASTM C1220-98 methodology, where the leaching condition was set at a temperature varying from $298 \mathrm{~K}$ to $363 \mathrm{~K}$ for 28 days. The release of cesium from ABG was in the permissible limit and followed the Arrhenius's law of a surface controlled reaction; its activation energy $\left(E_{a}\right)$ was $65.6 \pm 0.5 \mathrm{~kJ} / \mathrm{mol}$. Similar values of Ea were obtained for Boron $(64.3 \pm 0.5)$ and Silicon $(69.6 \pm 0.5 \mathrm{~kJ} /$ $\mathrm{mol})$ as the main glass network formers. In contrast, the dissolution mechanism of cesium from GGC was a rapid release, with increasing temperature, and the activation energy of Cs $(91.0 \pm 5 \mathrm{~kJ} / \mathrm{mol}) \mathrm{did}$ not follow any model related to carbon kinetic dissolution in water. Microstructure analysis confirmed the formation of Crystobalite $\mathrm{SiO}_{2}$ as a gel layer and $\mathrm{Cs}^{+1}$ valence state on the ABG surface.
\end{abstract}

(c) 2012 Elsevier B.V. All rights reserved.

\section{Introduction}

The fuel of the Very High Temperature Reactor (VHTR) is composed of Tristructural Isotropic (TRISO) coated particles embedded in a graphite matrix. Although graphite is impermeable and chemically stable during an operation of a high temperature reactor, the porous structures of graphite facilitates release radionuclides to the biosphere [1]. Furthermore, it is expected that around $1770 \mathrm{~m}^{3}$ of irradiated graphite would be generated from only the fuel elements during 60 years of operation of a High Temperature Reactor (HTR), making waste minimisation an important target in the development of this technology [2]. In order to reduce waste volume, fuel compacts are generally pulverized to separate the low level waste graphite from high level waste fuel particles. These particles are then placed in a different matrix, such as glass or ceramic, for a long term disposal [3]. In our research, the process of intercalation of TRISO particles from its graphite matrix caused damage to the outer coating of TRISO particles and released fission products from the kernel. An intercalation with a high speed water jet, applied to a graphite matrix in parallel and then in

\footnotetext{
* Corresponding author.

E-mail address: nasirhamodi@yahoo.co.uk (N.H. Hamodi).
}

perpendicular direction, generated respectively $45.3 \%$ and $5.8 \%$ of TRISO particles without coating [4].

The process of simulation started from encapsulation of TRISO particles, doped with cesium oxide, into a matrix having a high chemical durability in water. Cesium is acting as a surrogate for the fission products during the separation of spent TRISO particles from their graphite matrix. The intercalation process will generate contaminated TRISO particles and graphite powder with cesium and other fission products. Fachinger et al. [5] used natural graphite with an inorganic pore filler (borosilicate glass) as a surrogate for irradiated graphite-in order to develop a closed pore waste form, suitable for immobilisation of irradiated graphite. In this study, glass-graphite composite (GGC) and alumina-borosilicate glass (ABG) were selected as a matrix for TRISO particles contaminated with cesium oxide. Synthetic graphite was used to simulate irradiated graphite. Irradiated graphite can be mechanically and thermally processed and subsequently used as a matrix for manufacturing glass-graphite composite. It has been previously shown that glass can be used as an inorganic pore filler to fill the intrinsic pores in that type of matrix and successfully encapsulate cerium oxide [6].

Most glass materials do not usually wet carbon or graphite surfaces but react with them producing a gaseous product. Yurkov et al. [7] investigated a procedure of binding two carbon composites, 
using glass, and found that the carbon surface should be modified to $\mathrm{SiC}$ layer in order to ensure a better bonding. In addition, a previous study also demonstrated that a binary $\mathrm{B}_{2} \mathrm{O}_{3}-\mathrm{SiO}_{2}$ glass can have a good wettability for carbon fibers. $\mathrm{B}_{2} \mathrm{O}_{3}$ itself wets graphite because of its planer structure [8]. The interaction of Outer Pyrolytic Carbon (OPyC) and Silicon Carbide (SiC) layers with ABG have been investigated at $1423 \mathrm{~K}$ [9]. The results of that study revealed that the SiC layer was more suitable for adhesion with ABG than OPyC. The oxidation of $\mathrm{OPyC}$ to $\mathrm{CO}_{2}$ prevented such an adhesion and resulted in a formation of a porous glass matrix.

Utilisation of glass and graphite, as a waste form, requires an appropriate waste disposal assessment that includes evaluation of their performance in the repository and understanding of their corrosion mechanisms. Glass and graphite are both recognised as excellent leach resistance materials. Graphite leach resistance $\left(3 \times 10^{-10} \mathrm{~g} / \mathrm{cm}^{2} /\right.$ day $)$ is of $5-6$ orders of magnitude better than other waste matrix materials, such as $\mathrm{ZrO}_{2}\left(6 \times 10^{-5} \mathrm{~g} / \mathrm{cm}^{2} /\right.$ day $)$ or glass $\left(4 \times 10^{-4} \mathrm{~g} / \mathrm{cm}^{2} /\right.$ day $)$ [10]. It should be noted that the graphite leach resistance was calculated from its theoretical free energy of hydration and does not correspond to other polycrystalline phase of carbon. Raman spectroscopy of carbon in GGC revealed that carbon is present as a mixture of graphite and disordered black carbon and therefore, the leach rate of GGC could be different from these values and needs to be evaluated. The chemical durability analyses of these matrices were derived from the rates and mechanisms of glass dissolution at temperatures ranging from $298 \mathrm{~K}$ to $363 \mathrm{~K}$. Experiments conducted at a high temperature $(>323 \mathrm{~K})$ often yield crystalline phases. Whereas for timescales and temperatures more representative for a long-term repository $(<373 \mathrm{~K})$, the formation of amorphous gels, associated with clay minerals and (hydro) oxides, is predominant [11].

Furthermore, reaction of $\mathrm{H}^{+}$and $\mathrm{OH}^{-}$ions with glass causes dissolution of glass precursors in a process called ion-exchange, which is followed by elemental diffusion [12]. The dissolution rate of each precursor depends on its activation energy and therefore needs to be evaluated. In a previous work, a static leach test was conducted in distilled water at a room temperature on borosilicate glass, containing real radioactive wastes [13]. The test was carried out for 900 days, exhibiting very low normalised leach rates (NL) of Sr$90,2 \times 10^{-8}\left(\mathrm{~g} / \mathrm{cm}^{2} /\right.$ day $)$ and Cs-137, $3 \times 10^{-8}\left(\mathrm{~g} / \mathrm{cm}^{2} /\right.$ day $)$. Almost all leach rates remained constant after 200 days at a room temperature. To date, there are few studies related to calculation of activation energy of crystalline nuclear waste glass above the room temperature, and none has evaluated the activation energies of glass bearing contaminated TRISO particles.

The aim of this study is to develop a matrix capable of retaining highly soluble Cs and to prevent its diffusion to the ground water through the matrix pores or cracks. We have performed leach tests at $298 \mathrm{~K}, 313 \mathrm{~K}, 323 \mathrm{~K}, 333 \mathrm{~K}, 343 \mathrm{~K}, 353 \mathrm{~K}$ and $363 \mathrm{~K}$ - in accordance to the American Standard for Testing Method (ASTM C1220-98) for monolithic waste form, in order to routinely examine the chemical durability of nuclear waste glasses [14]. It should be noted that cesium is thought to reside on the surface of the $\mathrm{SiC}$ layer during the separation of TRISO particles from their graphite matrix. The failure of the TRISO particles coating during that process depends on a methodology used for the separation (an acidic intercalation, a mechanical, a water jet, a thermal shock and oxidation). The presence of TRISO particles in a matrix (ABG, GGC) during the forming stage might cause cracks in the matrix. These cracks were formed due to the differences in thermal expansion coefficients from the host matrix. Also, consequently, thermal cracks during rapid cooling may appear in the final matrix. A pervious study showed that such cracks did appear when OPYC TRISO particles were imbedded in $A B G$, thus affecting the performance of the engineering barrier system (EBS) [8].
Table 1

The chemical composition of ABG in wt.\%.

\begin{tabular}{llllll}
\hline Glass & $\mathrm{SiO}_{2}$ & $\mathrm{Al}_{2} \mathrm{O}_{3}$ & $B_{2} \mathrm{O}_{3}^{*}$ & $\mathrm{CaO}$ & $\mathrm{Na}_{2} \mathrm{O}$ \\
$(\mathrm{ABG})$ & 72.2 & 9.74 & 8.2 & 4.4 & 5.46 \\
\hline
\end{tabular}

\section{Experimental procedure}

\subsection{Materials}

Two matrices were designed for encapsulation of TRISO particles, impregnated with cesium oxide, in order to justify their long-term disposal. In this work, TRISO particles with SiC as an outer layer, instead of the standard outer pyrolytic carbon (OPyC), were used. These TRISO particles have been embedded in the matrix at a low sintering temperature ( $973 \mathrm{~K}$ ). TRISO particles with a $500 \mu \mathrm{m}$ diameter zirconia kernel were used as surrogates. The particles were coated through a process of Fluidized Bed Chemical Vapour Deposition (FBCVD) [15]. The layers were coated according to the following thicknesses and sequence: $90 \mu \mathrm{m}$ of buffer carbon; $40 \mu \mathrm{m}$ of internal Pyrolytic Carbon (IPyC) and $40 \mu \mathrm{m}$ of the final SiC layer.

TRISO particles were impregnated with cesium, using a decomposition reaction of cesium carbonate $\left(\mathrm{Cs}_{2} \mathrm{CO}_{3}\right)$. These samples were then encapsulated in the GCC ( 50 wt.\% ABG, 50 wt.\% graphite) and $A B G$ matrices, and subsequently leach tested in order to estimate the leaching behaviour of Cesium after 28 days. ABG was prepared in our laboratory by melting-quenching method and crushed into powder for further processing. The chemical composition of ABG was identified using Electron Dispersive X-ray Spectroscopy (EDS), as given in Table 1 .

\subsection{Sample preparation}

A surrogate waste was prepared by mixing $10 \mathrm{~g}$ of TRISO particles with $1 \mathrm{~mol}$ of $\mathrm{Cs}_{2} \mathrm{CO}_{3}$. The mixture was heated in a platinum crucible, covered with a porous lid, located in a tube furnace. The tube furnace was under vacuum $\left(10^{-3} \mathrm{mbar}\right)$, at a temperature of $1023 \mathrm{~K}$ and the heating duration was $10 \mathrm{~h}$. The decomposition of $\mathrm{Cs}_{2} \mathrm{CO}_{3}$ occurred at $873 \mathrm{~K}[16]$ :

$\mathrm{Cs}_{2} \mathrm{CO}_{3} \rightarrow \mathrm{Cs}_{2} \mathrm{O}+\mathrm{CO}_{2}$

The decomposition of cesium oxide to cesium metal occurred at $773 \mathrm{~K}$ (Eq. (2)). The temperature of $1023 \mathrm{~K}$ was chosen to avoid vaporisation of cesium [17]. In our case, it was observed at around $1073 \mathrm{~K}$ (a temperature shift due to a thermal resistance).

$2 \mathrm{Cs}_{2} \mathrm{O} \rightarrow 4 \mathrm{Cs}+\mathrm{O}_{2}$

TRISO particles were cooled and immediately hot iso-statically sintered in ABG and GGC at 30 wt.\% of waste-loading, in order to prevent Cs vapour volatilisation. The impregnated particles were under a pressure of $500 \mathrm{MPa}$ and temperature of $1023 \mathrm{~K}$ during sintering. The holding time was $30 \mathrm{~min}$. It should be noted that TRISO particles were impregnated with a much higher concentration of Cs than their real concentration in the spent fuel. Indeed, the process can be called a spiking process as it amplifies the migration of highly soluble elements, such as $\mathrm{Cs}$, from waste forms (ABG, GGC).

The sintering occurred in a graphite die located in a muffle furnace under air atmosphere. Then, the die was removed and cooled to room temperature. The pellets were removed from the die and annealed for $1 \mathrm{~h}$ at $773 \mathrm{~K}$. The densities of the waste forms were measured by Archimedes method and were $2.19 \mathrm{~g} / \mathrm{cm}^{3}$ and $1.81 \mathrm{~g} / \mathrm{cm}^{3}$ for $A B G$ and GGC respectively, considering that the density of TRISO particles was $4.6 \mathrm{~g} / \mathrm{cm}^{3}$. The produced GGC matrix is 

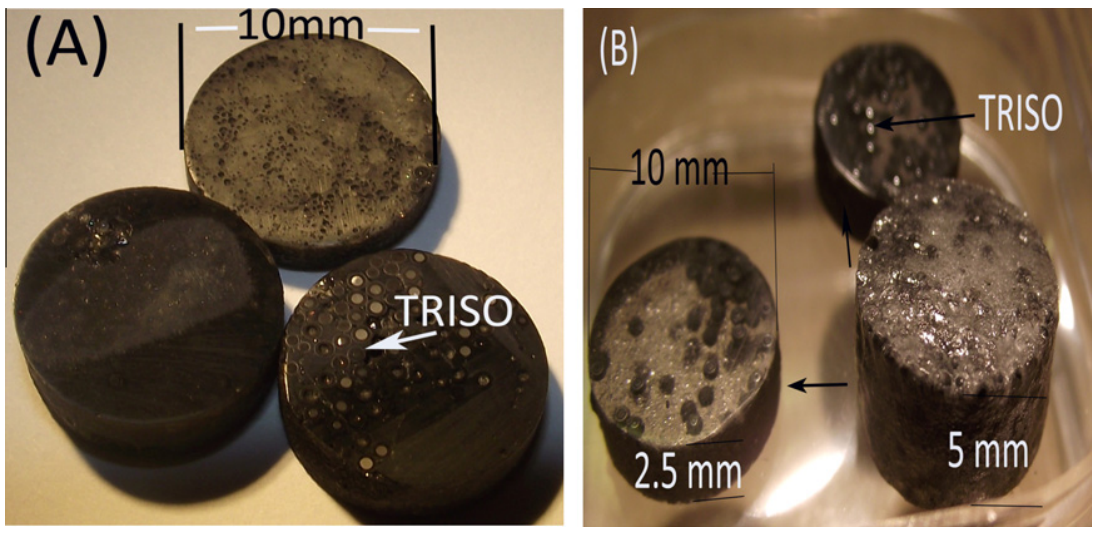

Fig. 1. (A) GCC matrix. (B) ABG matrix used for the leach test dimension $10 \mathrm{~mm} \times 2.5 \mathrm{~mm}$.

shown in Fig. 1A. The ABG matrix (5 mm thick) shown in Fig. 1B was divided into two disc-shaped specimens. Each specimen had dimensions of $10 \times 2.5 \mathrm{~mm}$ and was used for the leach test. In general, Fig. 1B shows that the distribution of particles appeared to be inhomogeneous due to migration of TRISO particles from the hot to the cold zone during sintering.

\subsection{Sample characterisation}

The interfaces of ABG-TRISO and GGC-TRISO were characterised by EDS, using a FEI/Philips XL-30 FEG-SEM. The cross section was ground, then polished with diamond polycrystalline paste (size of $0.1 \mu \mathrm{m}$ ) and then, it was coated with carbon in order to provide a sufficient electric conductivity to the specimen and prevent overlapping with cesium peak in the EDS spectra. In addition, the phase identification of $A B G$ and GGC, before and after leaching, was investigated using X-ray diffraction ( $\alpha$ source of $\mathrm{Cu}, 40 \mathrm{kV}$, Philips expert, Panalytical, Netherland) and Transmission Electron Microscope (TEM, Tecnai F30). Samples $(10 \times 10 \mu \mathrm{m})$ were extracted from the surface of $A B G$ and GGC, before and after leaching, using Focused Ion Beam (FIB). Fig. 2A shows that seven probes were cut out from each surface. These samples were thinned to $10 \mathrm{~nm}$ thickness using ion milling (Fig. 2B). It should be noted that these probes were brittle and all but one broke during ex-situ transfer from the surface to the TEM sample holder, using micro needle. Therefore, only one from the probes was successfully placed on the holder and investigated using TEM and X-ray photoelectron spectroscopy (XPS, Kratos Axis Ultra). This was necessary to investigate cesium valence state, before and after leaching, and to understand its behaviour during the leaching test. In the XPS analysis, photons of a specific energy are used to excite the electronic state of cesium atoms below the surface of the sample. Electrons ejected from the surface are energy filtered via a Hemi Spherical Analyser (HSA) before the intensity is recorded by the detector. While the X-ray may penetrate deep into the sample, the escape depth of the ejected electrons is limited. That is, for energies around $1400 \mathrm{eV}$, ejected electrons from depths greater than $10 \mathrm{~nm}$ have low possibility of leaving the surface without undergoing the loss energy effect.

The volumetric fractions of cesium in the matrices were identified, before and after the leaching test, using X-ray computed tomography. The instrument used in the procedure was Nikon Custom Bay $225 \mathrm{kV}$ X-ray, fitted with a multi-metal target, with an optimum spot size of $3 \mu \mathrm{m}$. During the analysis, the specimen was rotated $360^{\circ}$ and the projections were recorded on a $2 \mathrm{~K} \times 2 \mathrm{~K}$ Perkin Elmer 1621-16-bit amorphous silicon flat-panel detector with $\sim 200 \mu \mathrm{m}$ pixel pitch. A copper target was used and the resolution was $6.5 \mu \mathrm{m}$ for the specimen of a diameter
$10 \times 2.5 \mathrm{~mm}$. The following settings were used for the analysis; scanning time: $60 \mathrm{~min}$, voltage: $115 \mathrm{kV}$, current: $200 \mu \mathrm{A}$, gain: 1 , No. of frames: 1800 , the voxel size: $6.5 \mu \mathrm{m}$. The Ortho-slice of Xray tomography image is shown in Fig. $3 \mathrm{~A}$ and presents cesium, kernel, PYC, SiC and ABG. Cesium was randomly distributed between TRISO particles as an impregnation area and it was identified using threshold of the greyscale. The labelled data of TRISO particles and ABG without cesium are shown in Fig. 3B; and additionally with Cs in Fig. 3C.

Post processing of the raw $\mathrm{CT}$ data included data reconstruction using Nikon Metrolasis CT-Pro software (Metris XT 1.6, version 2.1.3509.24 387, 10 August 2009) and visualised using Avizo 7 standard edition visualisation software.

The disc-shaped samples of GGC and ABG were cleaned in an ultrasonic ethanol bath, dried and placed in seven sealed Teflon containers, equipped with sample holders filled with de-ionised water. The containers were kept in a multi scale temperatures oven at different temperatures: $298 \mathrm{~K}, 313 \mathrm{~K}, 323 \mathrm{~K}, 333 \mathrm{~K}, 343 \mathrm{~K}, 353 \mathrm{~K}$ and $363 \mathrm{~K}$. The ratio of the surface area of matrix to the volume of water $(\mathrm{SA} / V)$ was adjusted to be $10 \mathrm{~m}^{-1}$ by filling a suitable leachant volume. The SA: $V$ ratio was obtained from a similar study, using the ASTM-C1220 leach test for examining the chemical durability of glass, containing ion exchange resin doped with Cesium (Cs-Clino) [18]. The authors reported that the cumulative leach rate of Cs was $0.037 \times 10^{-6} \mathrm{~g} / \mathrm{cm}^{3}$ and the corresponding normalised leach rate $(\mathrm{NL})$ was $0.915 \times 10^{-6} \mathrm{~g} / \mathrm{cm}^{2} /$ day which is within the permissible limit. These values were obtained from a composite contained a 1:1 glass-ion exchange volume ratio (weight fraction of Cs was 0.078 in the matrix) heated to $313 \mathrm{~K}$ for 28 days.

\subsection{Water characterisation}

Water samples from each Teflon container were obtained and filtered using ultra-pure water filters. The concentrations of the elements in water were analysed using Inductive Coupled Plasma Mass Spectroscopy (ICP-MS). The detection limit of the elements dissolved in water was $10^{-9} \mathrm{~g} / \mathrm{cm}^{3}$. The standard deviation was $2-5 \%$ and it was measured basing on ten readings of ultra-pure water. The cumulative concentrations $\left(C_{i}\right)$ in water were measured in $\mathrm{g} / \mathrm{cm}^{3}$ from each container after 28 days. The concentrations of an element $(i)$ were converted to their normalised leach rates $\left(\mathrm{NL}_{i}\right)$ in the given equation [18].

$\mathrm{NL}_{i}=\frac{C_{i}}{\left(\frac{\mathrm{SA}}{V}\right) \cdot f_{i} \cdot t}$

where $C_{i}$ is the cumulative rate of element $(i)$ in $\mathrm{g} / \mathrm{cm}^{3}, t$ is the leaching time, $f_{i}$ is the mass fraction of the element $(i)$ in the waste 

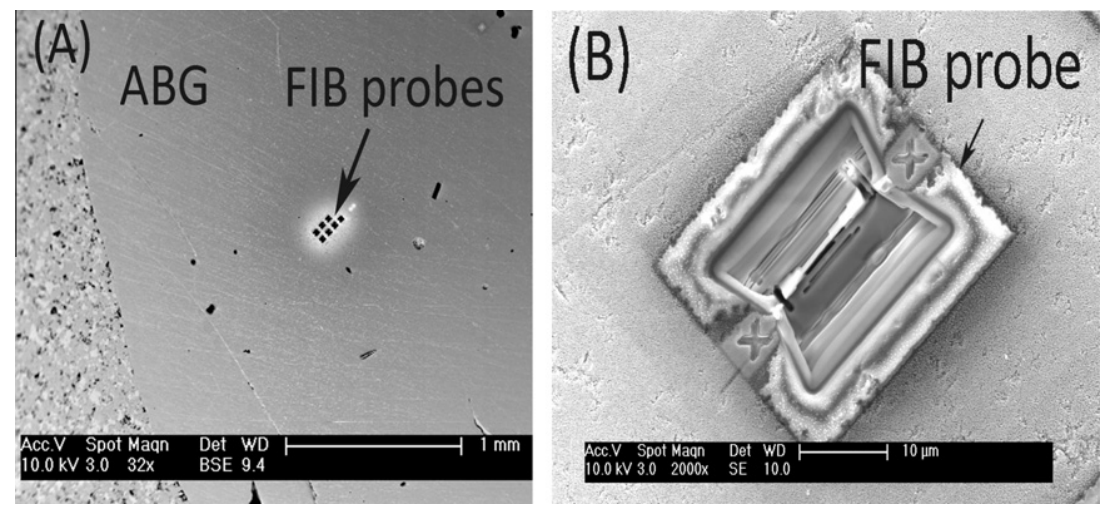

Fig. 2. (A) BSE image of ABG showing seven FIB probes taken from the ABG surface. (B) SEM image shows the dimension of the sample taken from the ABG and GGC surface.
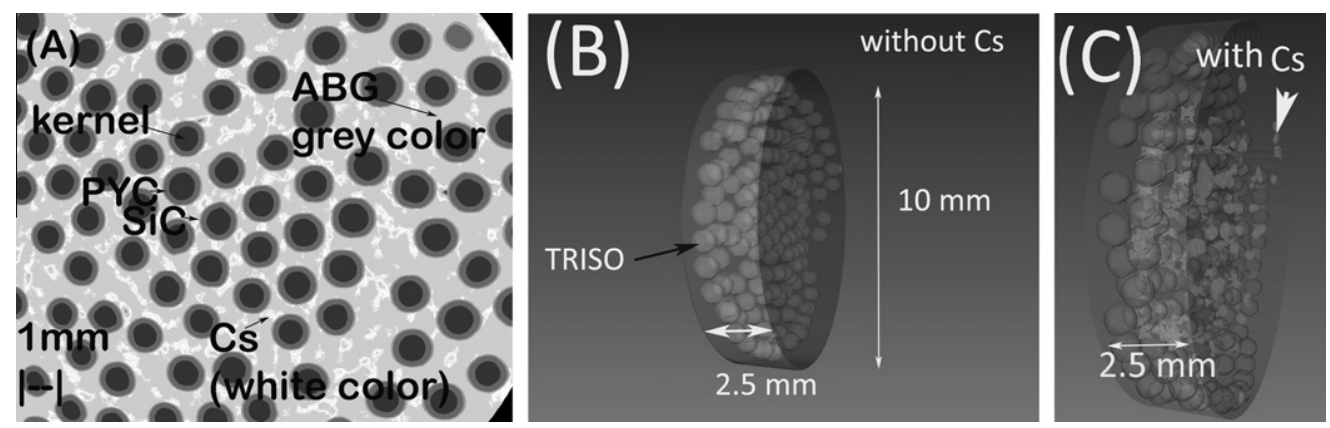

Fig. 3. (A) Labelled elements of ABG bearing TRISO particles. (B) Image of the specimen shows the distribution of TRISO particles without Cs. (C) Image of the specimen shows the distribution of Cs in pink colour.

matrix, and $\mathrm{SA} / \mathrm{V}$ is the ratio of surface area of matrix to the volume of water $(\mathrm{SA} / V)$.

The uncertainty in the mass fraction $(f)$ of Cs in ABG is based on the loss of $\mathrm{Cs}$ vapour from the matrix during sintering. The change of the total weight of TRISO particles, glass and $\mathrm{Cs}_{2} \mathrm{O}$ - before and after impregnation - revealed that Cs was lost due to volatilisation.

It should be noted that some studies neglected the volatilisation of cesium vapour during the sintering process in glass [18], thus causing a significant errors when calculating the initial concentration of Cs in the glass. Other studies used $\mathrm{TiO}_{2}$ as a network modifier to suppress the volatilisation of Cs from borosilicate glass [19]. However, the later decreased the chemical durability of the waste form. Thus it was necessary to use X-ray computed tomography to estimate the initial and final concentration of Cs in the matrix, before and after leaching, by calculating its volumetric fraction. Additionally, ICP-MS and EDS were not appropriate methods for this purpose because of non-uniform cesium distribution (Fig. 3C) in the sample that makes the estimation inaccurate.

\section{Results}

\subsection{Characterisation of TRISO particles}

The distribution of TRISO particles and Cs inclusions in ABG and GGC was measured using X-ray computed tomography. Visualisation of the images was performed using the Avizo 7 software. Each scan had a lattice dimension of $1538 \times 1538 \times 384$ voxels. This corresponded to disc-shaped sample of diameter of $10.0 \mathrm{~mm}$ and thickness of $2.5 \mathrm{~mm}$. A special image filter (Noise Gaussian Filter) was chosen after scanning the specimen in order to exclude noise voxels and minimise beam hardening effects from the kernel of

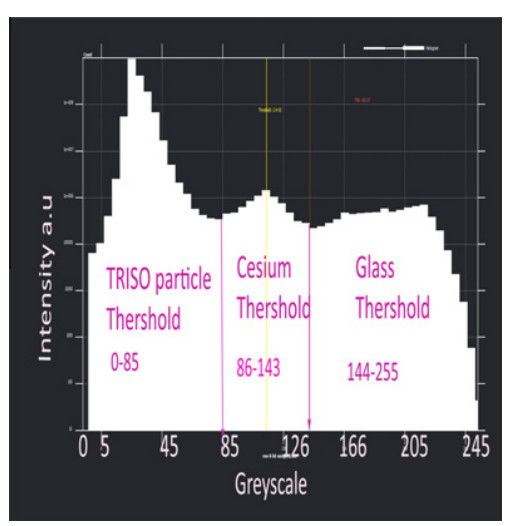

Fig. 4. Gray scale values of TRISO particles, cesium and ABG.

TRISO particles $\left(\mathrm{ZrO}_{2}\right)$. The beam hardening effect is due to the absorption of low energy X-rays at the surface of the very dense

Table 2

Volume fractions of the materials in ABG.

\begin{tabular}{lrlll}
\hline Material & \multicolumn{1}{l}{ Count } & Deviation & Volume & vol.\% \\
\hline Kernel & $13,13,144$ & 255 & 4.005 & 1.17 \\
PYC & $23,57,263$ & 251 & 16.57 & 4.83 \\
SiC & 38,576 & 163 & 1.9 & 0.55 \\
ABG & $542,08,852$ & 244 & 307.1 & 90.00 \\
Cesium & $22,76,471$ & 164 & 10.24 & 2.99 \\
Void & 10,661 & 32 & 1.568 & 0.45 \\
\hline
\end{tabular}



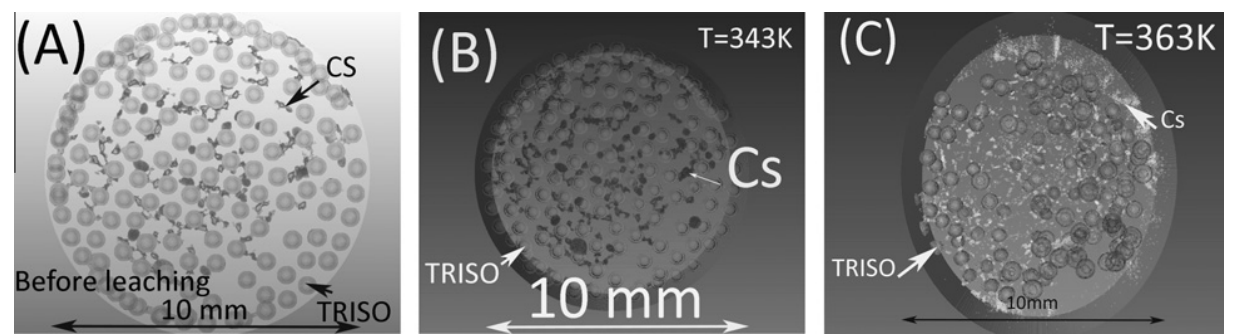

Fig. 5. (A) Topview of ABG includes TRISO particles and Cs before leaching. (B) Topview image of same ABG includes TRISO particles and Cs after leaching at $343 \mathrm{~K}$. (C) Topview image of same ABG includes TRISO particles and Cs after leaching at $363 \mathrm{~K}$.

$\mathrm{ZrO}_{2}$ kernel, causing noise to the greyscale of the other elements ( $\mathrm{PyC}, \mathrm{SiC}$ and $\mathrm{Cs}$ ).

The results of the distinct tri-peak grey-scale distribution are shown in Fig. 4. It was possible to use a minimum threshold to differentiate $\mathrm{Cs}$ from $\mathrm{SiC}$, pyrolytic carbon, $\mathrm{ZrO}_{2}$ of TRISO particles and the surrounding glass. The volumetric fractions of the segmented data in ABG, bearing TRISO particles, are listed in Table 2.

A sensitivity analysis of the Grey-Scale Value (GSV) distribution was carried out at three increments of $10 \%, 25 \%$ and $100 \%$, both above and below the GSV. An error of less than $2 \%$ could be achieved by selecting a GSV within \pm 25 points of the actual minimum. Segmented voxels were then analysed using the material statistic features in the Avizo software, in order to determine the volume fraction of each material. The percentage volumetric fractions of $\mathrm{Cs}\left(V_{\mathrm{cs}} / V_{\text {matrix }}\right)$ in ABG was $2.99 \pm 0.06$ vol.\%. The same procedure was performed on GGC specimen, so the volume fraction of Cs was $2.5 \pm 0.06$ vol.\%. The initial weight fraction $f_{\mathrm{Cs}}$ was $0.139 \pm 0.00278$ in ABG and $0.116 \pm 0.00232$ in GGC. It was calculated using the density of cesium oxide $\left(4.65 \mathrm{~g} / \mathrm{cm}^{3}\right)$, basing on the following equation:

$f_{\mathrm{Cs}}=\frac{V_{\mathrm{Cs}} \cdot \rho_{\mathrm{Cs}}}{V_{\text {matrix }} \cdot \rho_{\text {matrix }}}$

where $V_{\mathrm{Cs}}$ is the cesium volumetric fraction in the matrix, $\rho_{\mathrm{cs}}$ is the density of cesium oxide, $V_{\text {matrix }}$ and $\rho_{\text {matrix }}$ is the volume and the density of the matrix respectively.

The top view X-ray tomography image of ABG sample, before leaching, is shown in Fig. 5A. The top view of the same specimen, after leaching at $343 \mathrm{~K}$, shows minor change in the distribution of Cs (Fig. 5B). It was not possible to determine the difference in the volume fractions of Cs in the matrix, before and after leaching. This was due to low resolution of the X-ray tomography $(>6.5 \mu \mathrm{m})$, required for detection of small quantities of Cs loss within the matrix. The volume fraction of Cs in ABG after leaching at $343 \mathrm{~K}$ and $363 \mathrm{~K}$ was $(2.99 \pm 0.06)$, and in GGC was $2.5 \pm 0.06$ vol.\%. However, the distribution of $\mathrm{Cs}$ in $\mathrm{ABG}$ (labelled in yellow) was changing with increasing temperature of leaching, as shown in Fig. 5C.

The characterisation of the thickness of SiC layer in TRISO particles, before embedding, was carried out using EDS. Fig. 6A shows TRISO particles before impregnation and embedding in the matrix. $\mathrm{X}$-ray elemental mapping in Fig. 6B shows that TRISO particles, dopped with $\mathrm{Cs}_{2} \mathrm{O}$, were randomly dispersed on the $\mathrm{SiC}$ layer and diffused only in the direction of the glass matrix. Fig. 6B also shows that $\mathrm{SiC}$ layer was attacked during sample impregnation. The corrosion of SiC layer was measured basing on differences in its thickness before (Fig. 6A) and after embedding (Fig. 6B). The thinning of $\mathrm{SiC}$ was non-uniform and was around $20 \mu \mathrm{m}$. The depletion occurred due to the reaction of $\mathrm{Cs}_{2} \mathrm{O}$ with $\mathrm{SiC}$ during an early stage of impregnation, suggesting that there was an oxidation of $\mathrm{SiC}$ to $\mathrm{SiO}_{2}$ and carbon. EDS analysis confirms the presence of Cs impregnation, as shown in Fig. 6C.

\subsection{Leach test}

The static leach test of Cs in both matrices is designed to simulate a near equilibrium condition or long term leaching. The leach test was conducted according to the international standard (ASTM C1220), which provides a measure of the chemical durability of simulated or radioactive monolithic waste form, such as glass, ceramic and cement, at a temperature below $373 \mathrm{~K}$. The test was conducted in de-ionised water $(\mathrm{pH} 7)$ at $298 \mathrm{~K}, 313 \mathrm{~K}, 323 \mathrm{~K}$, $333 \mathrm{~K}, 343 \mathrm{~K}, 353 \mathrm{~K}$ and $363 \mathrm{~K}$ for 28 days. High temperature enhances the leaching process by increasing the diffusion and reaction rates of the glass constituents [20]. Water samples were taken from each Teflon container at the end of the leach test (28 days) and were analysed using ICP-MS in order to calculate B, $\mathrm{Si}$ and $\mathrm{Cs}$ concentrations. The cumulative leach rates of boron $C_{B}$, silicon $\mathrm{C}_{\mathrm{Si}}$ and Cesium $\mathrm{C}_{\mathrm{cs}}$ from $\mathrm{ABG}$ samples and cumulative leach rates of carbon $C_{C}$ and cesium $C_{C s}$ from GGC are given in Table 3. All leachant data obtained in this study are well within the reproducibility range of the standard reference data. The concentrations of the elements were averaged from 10 readings of ICP-MS. No water samples were taken during the leaching experiment to avoid interruption of the dissolution rate. After performing the leach test, all samples were cleaned with acetone, dried and analysed using SEM, $\mathrm{X}$-ray diffraction and X-ray tomography.

The normalised leach rates $(\mathrm{NL}) \mathrm{g} / \mathrm{cm}^{2} /$ day of $A B G$ and GGC were calculated using Eq. (3) and cumulative concentrations are given in Table 3. The weight fraction of Cs $\left(f_{\mathrm{cs}}\right)$ was 0.139 for ABG and 0.116 for GGC; SA $/ V$ was $10 \mathrm{~m}^{-1}$. The normalised leach rate (NL) of ABG and GGC are plotted against temperature in Fig. 7.

The leach test results from ABG (Fig. 7) show that the normalised leach rates of the major glass elements were based on the sequence $\mathrm{Si}<\mathrm{B}<\mathrm{Cs}$. The value of $\mathrm{NL}_{\mathrm{Cs}}$ was increased by two orders of magnitude from $0.2 \times 10^{-6} \mathrm{~g} / \mathrm{cm}^{2} /$ day to $2.05 \times 10^{-5} \mathrm{~g} / \mathrm{cm}^{2} /$ day at temperature rising from $298 \mathrm{~K}$ to $363 \mathrm{~K}$. The value of $\mathrm{NL}_{\mathrm{cs}}$ $\left(0.77 \times 10^{-6} \mathrm{~g} / \mathrm{cm}^{2} /\right.$ day $)$ at $313 \mathrm{~K}$ was lower than $\mathrm{NL}_{\mathrm{cs}}$ $\left(0.907 \times 10^{-6} \mathrm{~g} / \mathrm{cm}^{2} /\right.$ day $)$ obtained by Joui et al. [18] at the same temperature, using ASTM C1220-98. Conversely, the value of $\mathrm{NL}_{\mathrm{Cs}}$ from GGC obtained from Fig. $7\left(4.4 \times 10^{-6} \mathrm{~g} / \mathrm{cm}^{2} /\right.$ day $)$ was about one order of magnitude higher than the corresponding $\mathrm{NL}_{\mathrm{Cs}}$ in $\mathrm{ABG}$, at the same temperature regimes. It suggests that GGC matrix in this experiment failed to establish a stable engineering barrier to retain radionuclides within the matrix. The dissolution rates of $\mathrm{Cs}$ and glass precursors at different temperature regimes were plotted in Fig. 8 that follows the law of Arrhenius for correlation between a dissolution rate and a temperature. If a given crystalline waste form is stable in the presence of an aqueous medium, then the only reaction during leach testing is a gradual saturation of the solution (in a closed system) or a continuous removal of solids (in an open system). Such reactions appear to follow the Arrhenius equation, as reported by Crawford et al [21]. The Arrhenius' law of kinetic dissolution of glass and ceramic matrices in Eq. (5) represents the dissolution kinetics in a variety of waste forms: glass, ceramics, and 

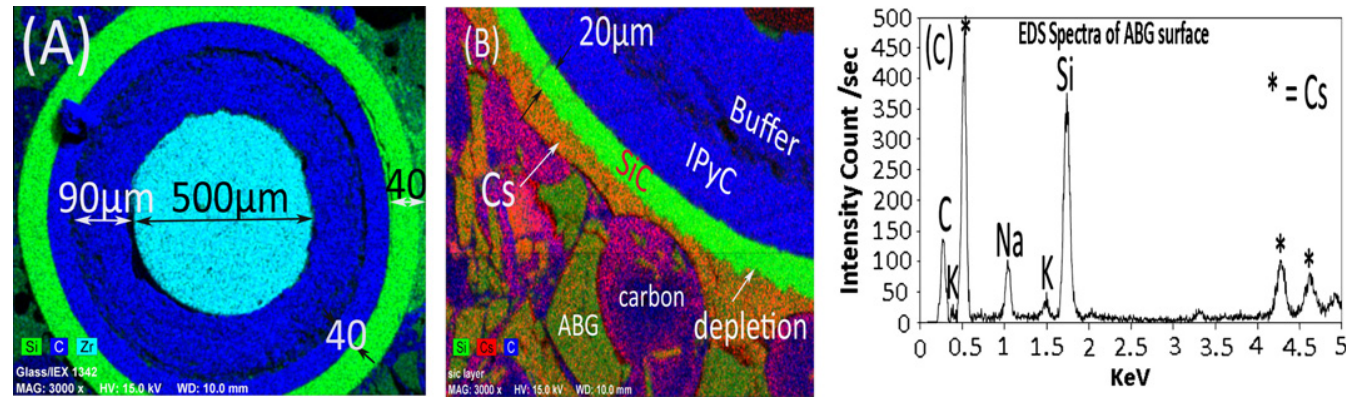

Fig. 6. (A) Xray mapping of TRISO particles before embedding. (B) X-ray mapping TRISO particles after embedding shows Cs deposition and remaining SiC layer (around $20 \mu \mathrm{m})$. (C) EDS pattern of $\mathrm{Cs}_{2} \mathrm{O}$ show the Cs peaks and glass precursors.

Table 3

Cumulative leach rates in $\mu \mathrm{g} / \mathrm{cm}^{3}$ of $\mathrm{B}, \mathrm{Si}$ and $\mathrm{Cs}$ from $\mathrm{ABG}$ and $\mathrm{GGC}$ at various temperatures.

\begin{tabular}{|c|c|c|c|c|c|c|c|}
\hline \multirow[t]{2}{*}{ Elements } & \multicolumn{7}{|c|}{ Temperature (K) } \\
\hline & 298 & 313 & 323 & 333 & 343 & 353 & 363 \\
\hline \multicolumn{8}{|l|}{$A B G$} \\
\hline $\mathrm{Si}$ & 0.01 & 0.0552 & 0.099 & 0.185 & 0.35 & 0.89 & 1.25 \\
\hline B & 0.014 & 0.0315 & 0.0611 & 0.099 & 0.3169 & 0.723 & 1.233 \\
\hline Cs & 0.021 & 0.0649 & 0.09 & 0.153 & 0.611 & 1.613 & 2.9179 \\
\hline \multicolumn{8}{|l|}{ GGC } \\
\hline C & 0.1667 & 0.198 & 0.976 & 1.297 & 1.087 & 2.82 & 1.56 \\
\hline Cs & 0.091 & 0.2946 & 0.5967 & 1.296 & 6.146 & 29.05 & 59.367 \\
\hline
\end{tabular}

individual crystalline components. The activation energy of a reaction is the minimum energy required to start a chemical reaction. Therefore, the activation energy for an element reflects its dissolution rate in water, which depends on its bonding strength with silicon and boron, as main network formers.

$\mathrm{NR}=\mathrm{NR}_{0} e^{-E_{a} / R T}$

where $\mathrm{NR}_{0}$ is the leach rate at infinity temperature, $E_{a}$ is the Activation energy, $R$ is the gas constant $8.13 \mathrm{~J} / \mathrm{mol} \mathrm{K}$, and $T$ is the leach temperature from $298 \mathrm{~K}$ to $363 \mathrm{~K}$.

Fig. $8 \mathrm{~A}$ and $\mathrm{B}$ shows the expected exponential increase in the dissolution rate of $A B G$ and $G G C$ respectively, from $298 \mathrm{~K}$ to $363 \mathrm{~K}$. Activation energies have been determined for Si, Cs and B (sometimes used as a glass tracker) from the gradient of the line fitting the natural logarithm of NL points in the graph. The activa- tion energy of $\mathrm{B}$ is $64.3 \pm 0.5 \mathrm{~kJ} / \mathrm{mol}$, for Cs is $65.6 \pm 0.5 \mathrm{~kJ} / \mathrm{mol}$ and for $\mathrm{Si}$ is $69.6 \pm 0.5 \mathrm{~kJ} / \mathrm{mol}$.

\section{3. $X R D$ and TEM}

The surface of ABG was investigated, using X-ray diffraction, in order to identify different phases of glass and crystalline inclusions. The XRD patterns displayed in Fig. 9 shows microstructure of $A B G$ before pressing as an amorphous phase (green spectra). The XRD pattern of ABG bearing TRISO/Cs particles, before leaching, shows minor formation of $\mathrm{SiO}_{2}$ and turbo-static carbon on the surface (black spectra). However, the XRD pattern of ABG, after leaching, shows major formation of Crystobalite $\mathrm{SiO}_{2}$ (red spectra). This change in the surface composition commonly alters the observed properties of the surface, most notably enhancing corrosion resistance. The formation of amorphous silica barrier was also observed in the surface layer of the SRL 200S glass after leaching test in water for 182 days [22]. However, the rate controlling effect of this layer was not established. This layer was heterogeneous and non-uniform over the surface of ABG - as shown in the SEM image, displayed in Fig. 10A. The Figure shows a vertical cross section of the $A B G$ specimen after leaching at $363 \mathrm{~K}$. The thickness of $\mathrm{SiO}_{2}$ layer was varied along with the ABG surface and displayed in the Back-Scattered Electron (BSE) image in Fig. 10B.

Cesium was not detected in the ABG surface by XRD, possibly due to its small concentration. Therefore, it was necessary to investigate the surface using TEM and XPS, in order to identify cesium phase before and after leaching, and the inclusion sizes of cesium in the final matrix. A few samples were extracted (Fig. 2B) for investigation using TEM. Fig. 11A shows ABG surface
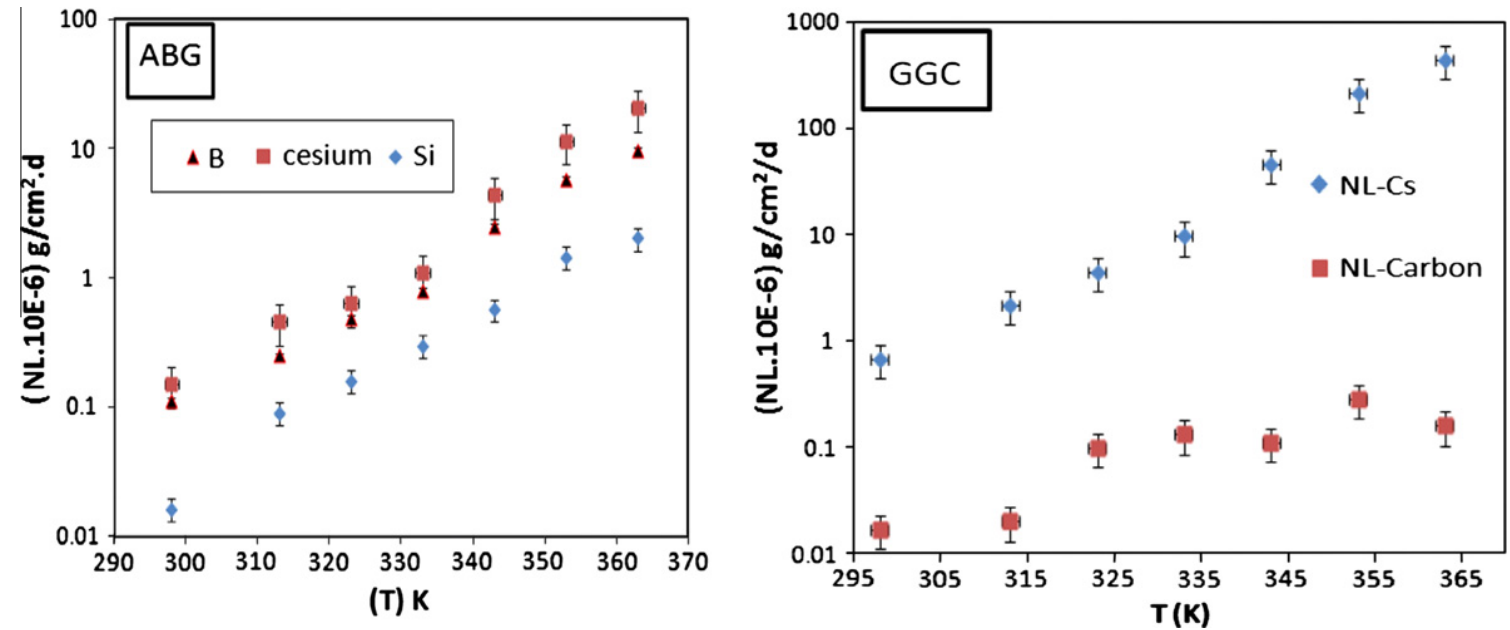

Fig. 7. NL-ABG dissolution correlation with temperature and NL-GGC correlation with temperature in errors bars. 

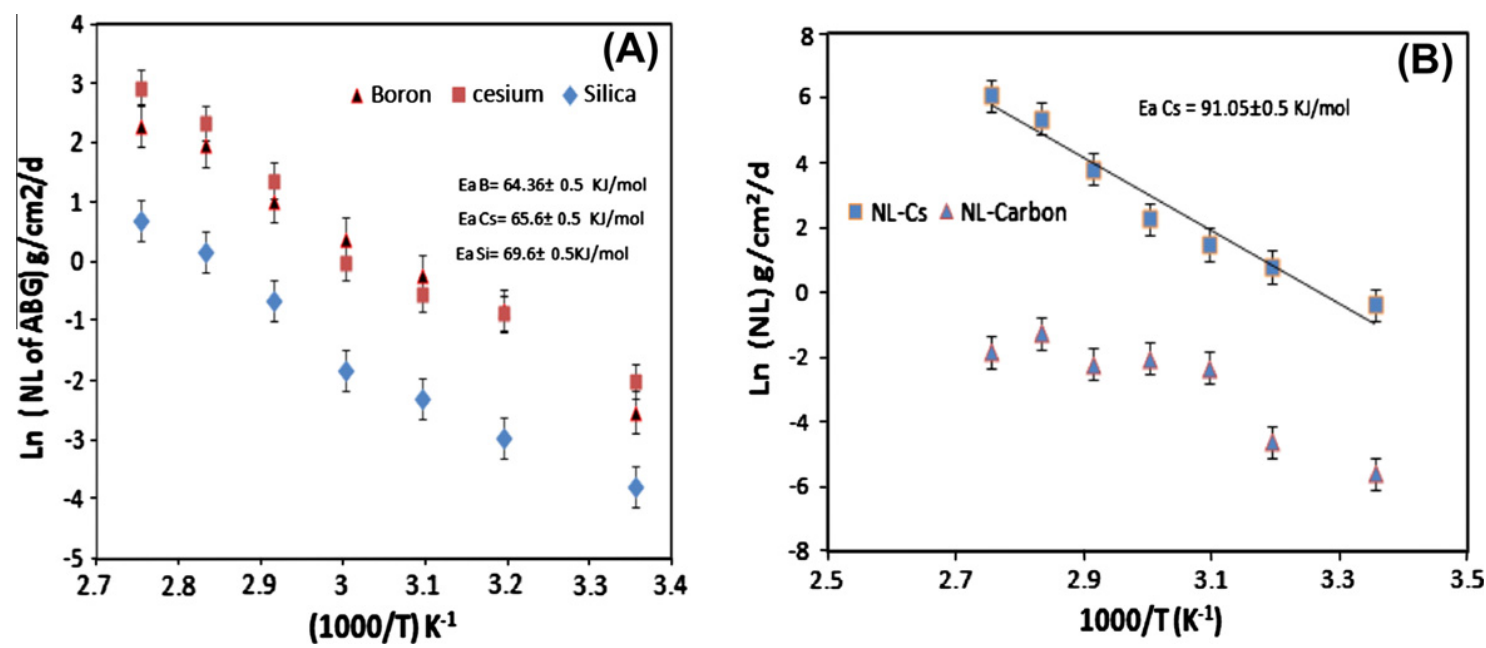

Fig. 8. (A) Normalised leaching rate of $\mathrm{Si}, \mathrm{B}$ and $\mathrm{Cs}$ from ABG in errors bars. (B) Normalised leaching rate of Si, B and Cs from GGC in errors bars.

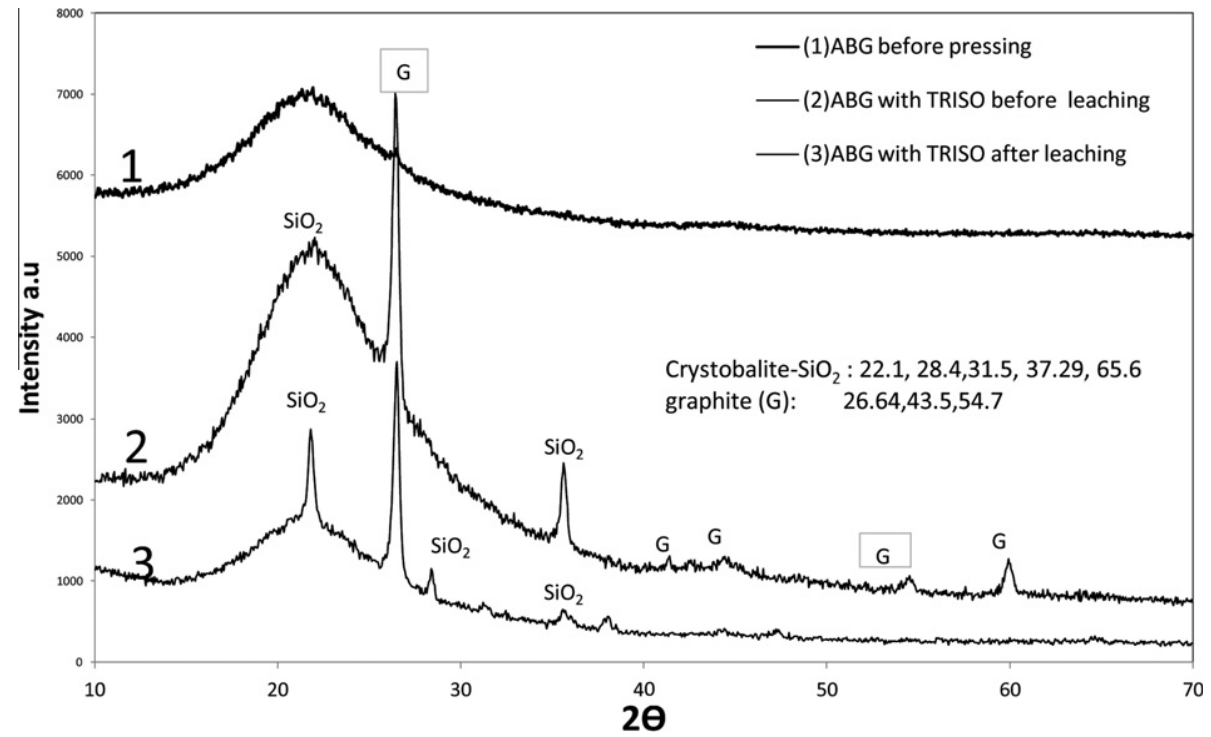

Fig. 9. XRD spectra of ABG surface: (1) before pressing, (2) after pressing and before leaching, (3) after leaching.
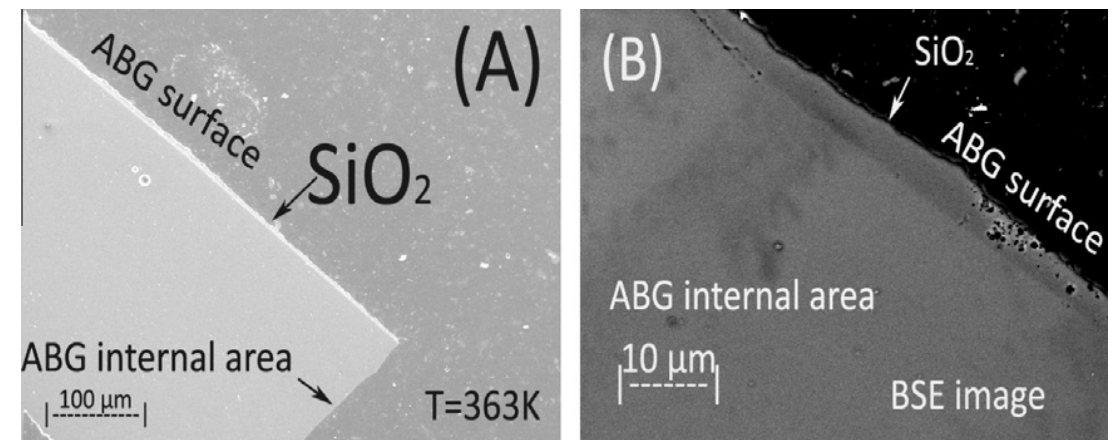

Fig. 10. (A) SEM image of ABG surface after leaching at $363 \mathrm{~K}$ shows $\mathrm{SiO}_{2}$ layer. (B) $\mathrm{BSE}$ image of the same area shows non-uniform formation of $\mathrm{SiO} \mathrm{O}_{2}$ layer over the $\mathrm{ABG}$ surface.

before leaching and Fig. 11B, C and D shows ABG after leaching at $343 \mathrm{~K}, 353 \mathrm{~K}$ and $363 \mathrm{~K}$ respectively. It is important to know that FIB probes from GGC were not successfully placed on TEM sample holder (carbon film on copper grid), because these samples have a weak structure and all probes were broken during the ex-situ transfer from GGC surface to the sample holder, using micro needle. Therefore, no analyses were established to examine Cs inclusion in GGC.

\subsection{X-ray photoelectron spectroscopy}

X-ray photoelectron spectroscopy is based on the photoelectric effect. When materials are bombarded with X-rays, energetic enough to eject electrons from inner or valence shells, the difference between the incoming photon energy and electron binding energy (BE) is converted to kinetic energy of the escaping photoelectron. We have used XPS as a surface sensitive technique because it is 

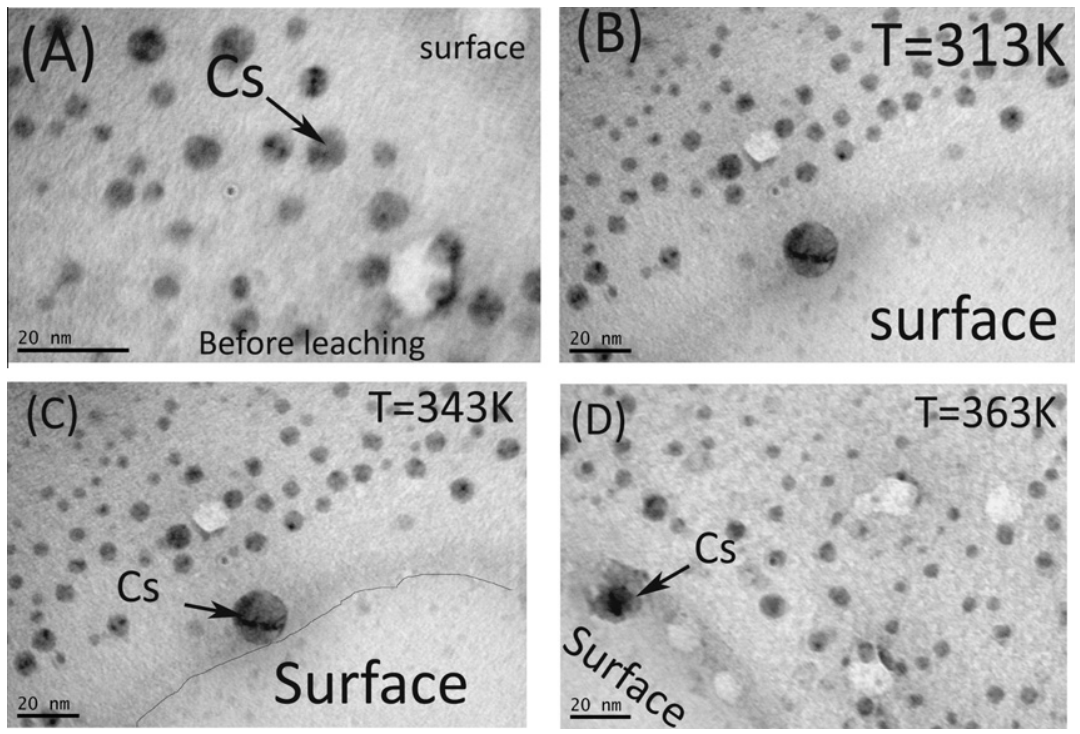

Fig. 11. (A) TEM image of ABG surface before leaching. (B) TEM image of ABG surface after leaching at $313 \mathrm{~K}$. (C) TEM image of ABG surface after leaching at $343 \mathrm{~K}$. (D) TEM image of ABG surface after leaching at $363 \mathrm{~K}$.
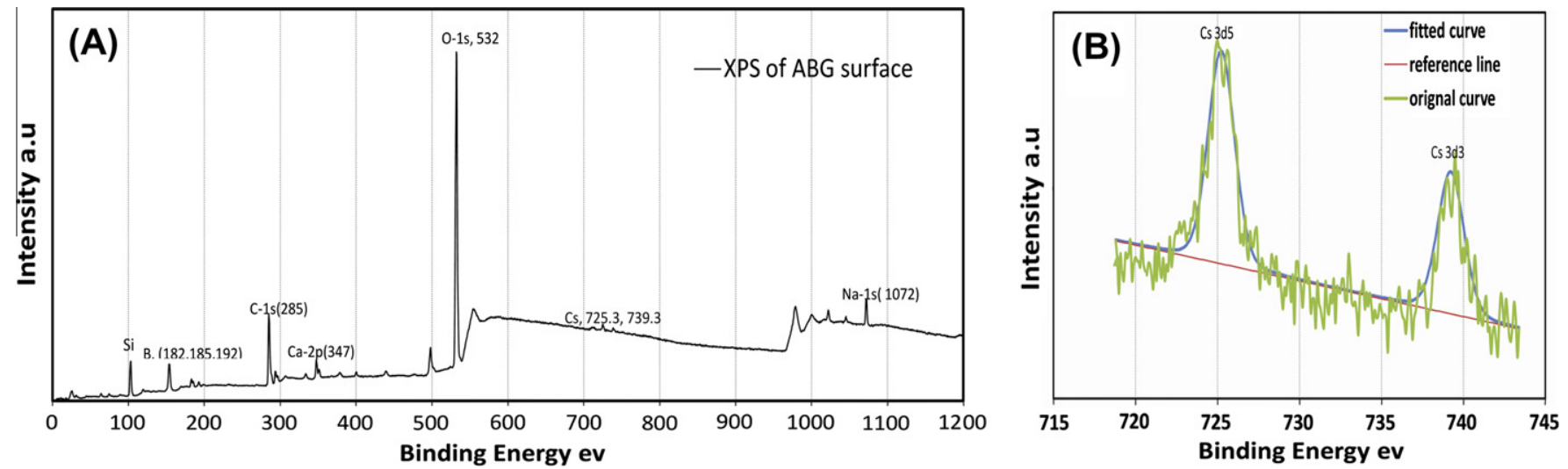

Fig. 12. (A) XPS spectra of all elements in ABG surface. (B) Narrow scan of XPS spectra for cesium.

based on detection of photoelectrons which have, essentially, undergone no inelastic collisions. This can only happen if the atoms, from which electrons are ejected, are located near the surface. The depth of analysis is therefore typically between 10 and $50 \AA$ [23].

A broad survey spectrum was collected, in the $0-1100 \mathrm{eV}$ energy range, using a high-sensitivity but low-resolution data-collection mode $(1 \mathrm{eV} / \mathrm{step})$. The survey scan was taken before/after a leaching test and then followed by a narrower scan, typically $700-750 \mathrm{eV}$, with a lower sensitivity but a higher resolution $(0.065 \mathrm{eV} / \mathrm{step})$ for cesium interest. The elements shown in Fig. 12A represent all major cations, anticipated or observed in the sample, including silicon $(\mathrm{Si})$, sodium $(\mathrm{Na})$, carbon $(\mathrm{C})$, cesium $(\mathrm{Cs})$, calcium (Ca) and the anion oxygen $(\mathrm{O})$. In addition, a narrow scan of cesium (Cs) was also included when analysing samples.

Cesium was detected on all ABG and GGC surfaces exposed to that ion. A representative spectrum of the Cs-3d photoelectric peak is shown in Fig. 12B. The reported BE for Cs metal is $726.0 \mathrm{eV}$, for cesium hydroxide it is $724.5 \mathrm{eV}$ and for cesium oxide it is $725.3 \mathrm{eV}$ [24]. The measured chemical shifts were approximately $0.7 \mathrm{eV}$, resulting in BEs between $725.3 \mathrm{eV}$ and $726.0 \mathrm{eV}$ - obtained from the curve fit shown in Fig. 12B. Therefore, no trace of cesium metal was detected and cesium valence state was in a form of +1 in oxide phase.

\subsection{SEM of GGC}

The microstructure of GCC was examined using high magnification SEM (Fig. 13A) for glass and graphite interface. Fig. 13B shows the interfacial bonding between those semi-molten glass particles and graphite particles in GGC which revealed that GGC contained nano-porosity. That could be the reason for the high release rates of Cs in water. It is possible then, that for this type of porous structure, Cs escaped by a diffusion controlled process, due to water penetrating through these pores and the high solubility of Cs in water [25]. The density of GGC, bearing TRISO particles, was $1.81 \mathrm{~g} / \mathrm{cm}^{3}$ estimated using the Archimedes method. The theoretical density of $2.05 \mathrm{~g} / \mathrm{cm}^{3}$ was estimated using volumetric fraction of the glass and graphite without pores; density of graphite was taken as $.9 \mathrm{~g} / \mathrm{cm}^{3}$ and for glass $2.2 \mathrm{~g} / \mathrm{cm}^{3}$ [6]. This is not consistent with a previous study that demonstrated that it was possible to obtain composite density near to its theoretical density, due to the semi-molten glass, filling the pores between the graphite particles. This was achieved using cerium oxide powder as a surrogate for 

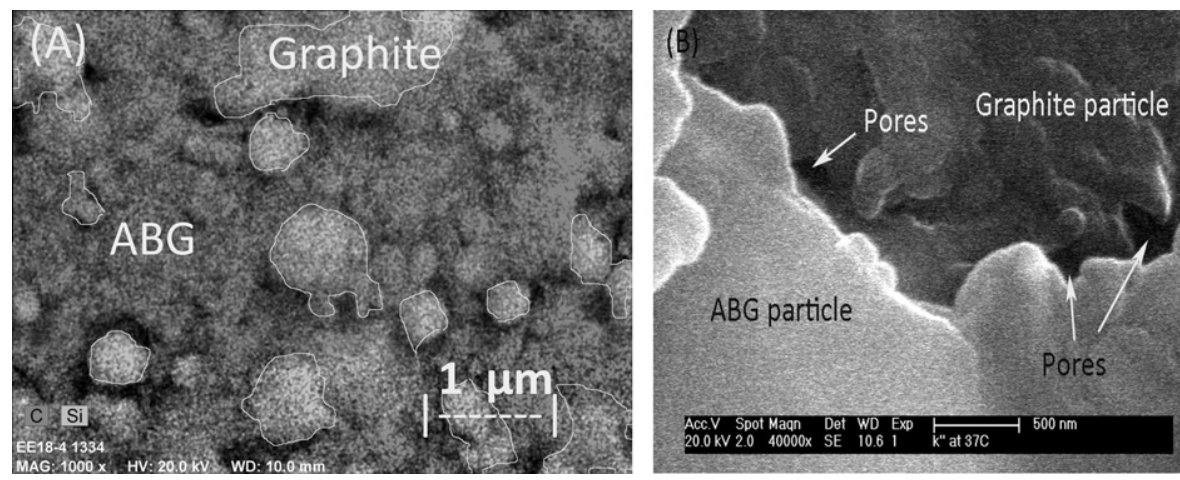

Fig. 13. (A) X-ray mapping of GGC surface shows the semi-molten glass filling the graphite pores. (B) SEM image shows open pores at the interface area between graphite and glass particles in the GGC matrix.

TRISO particles in GGC [8]. It is possible then, that the differences in size between TRISO particles (around $1 \mathrm{~mm}$ ) and $\mathrm{CeO}_{2}$ powder (grain size $1 \mu \mathrm{m}$ ), or the differences in thermal expansion coefficient between TRISO particles and GGC, during cooling process, affected the microstructure and resulted in the nucleation of pores in the composite.

\section{Discussion}

\subsection{Leach test results}

Cesium oxide is volatile, has very high solubility in water and can diffuse rapidly out of the engineering barrier system to the biosphere. The impregnation of TRISO particles with cesium oxide was intended to be an analogue or a simulation of fission product contamination, occurred during a specific stage of intercalation of TRISO particles from its graphite matrix. Cesium was used as a dissolution tracker from the $A B G$ and GGC matrices to the water and compares it with boron and silicon.

We have observed that $\mathrm{SiC}$ was oxidised during the impregnation at a sintering temperature $(1023 \mathrm{~K})$ due to its reaction with free oxygen. The depletion of the $\mathrm{SiC}$ layer was around $20 \mu \mathrm{m}$. However, it is still considered as an effective barrier to the migration of fission products from the kernel in case of real radioactive TRISO particles. The depletion process of $\mathrm{SiC}$ embedded in alkaline borosilicate glass was confirmed by a previous study that used TRISO particles with thin outer SiC layer $(10 \mu \mathrm{m})$ [8].

Our current results show that GGC was unable to properly retain Cs within the matrix due to the existence of nano-pores. With the current preparation procedure, ABG appears to be a more suitable candidate for waste encapsulation. The release of Cs from GGC exceeded the permissible limit of NL dissolution in water $\left(0.915 \times 10^{-6} \mathrm{~g} / \mathrm{cm}^{3}\right)$ at $313 \mathrm{~K}$ which was mentioned in Juoi el.at [18]. However, the release of Cs from ABG in our study, at the same temperature, was lower than the permissible value, suggesting that the chemical durability of alumina-borosilicate glass is acceptable for immobilisation of contaminated TRISO particles. The similarities in the activation energies between different precursors of the glass matrix suggest that Cs oxide was trapped and incorporated in the $A B G$ network during the sintering process with TRISO particles. This was not the case for the GGC where cesium oxide could diffuse to the penetrating water through the nano-pores. It is possible that this porosity was formed during hot isostatic sintering. Therefore, it might be feasible to increase the tightness of the GGC matrix by increasing the glass fraction in the composite. Further experiments will also be required in order to ensure a low leaching rate for any future graphite/glass composite. This will provide strong evidence on the feasibility of reusing irradiated graphite as a matrix for a long term disposal.
The formation of a secondary phase on ABG surface was confirmed by a similar Russian study [26], examining the chemical durability of radioactive borosilicate glass (K-26) during 12 years of testing it in loamy soil, at a temperature ranging from -30 to $+10^{\circ} \mathrm{C}$. In that work, a protective layer was formed on the glass surface that had been interacted with the repository environment. The layer was morphologically similar to the bulk waste glass. However, it was chemically inhomogeneous and non-uniform in thickness and structure. In our study, a reduction in the leach rate of Si, B and Cs was observed at a temperature ranging from 350 to $363 \mathrm{~K}$, as denoted by the change in the slope of the line fitting NL rates in Fig. 7-ABG graph. It might also be that saturation of $\mathrm{Si}, \mathrm{B}$ and $C s$ ions in water, at a higher temperature, had a major impact on suppression of the dissolution rate. This means that the saturation of $\mathrm{Si}$, B and Cs in water allowed the leachant concentration of Si to reach the solubility limit in water, which consequently results in low leach rates.

\subsection{Activation energy of glass precursors}

The activation energy of the released carbon from GGC could not be estimated due to inconsistency in the behaviour of normalised leach rate with increasing temperature, as shown in Fig. 8B. The activation energy of Cs $(91.0 \pm 5 \mathrm{~kJ} / \mathrm{mol})$ was estimated from Arrhenius's law.

The similarities between the activation energies of B, Cs and $\mathrm{Si}$ $(64.3 \mathrm{~kJ} / \mathrm{mol}, 65.6 \mathrm{~kJ} / \mathrm{mol}, 69.6 \mathrm{~kJ} / \mathrm{mol}$ respectively) were not related to a diffusion process as the diffusion of these elements (diffusion through glass matrix) has to take place at much higher temperatures $(>825 \mathrm{~K})$ for a longer time $(\sim 500 \mathrm{~h})$ [27]. Therefore, we suggest that the process of ion exchange with $\mathrm{OH}^{-1}$ and $\mathrm{H}^{+}$ was the predominate parameter of glass dissolution. It is important to note that actual storage of the nuclear waste takes place at much lower temperatures (400-750 K), thus the measurement of the diffusion rates in this range is not practical [27]. The process of dissolution in our study was related to the breaking of the Cs-B-Si-O bonds in the glass surface by the $\mathrm{OH}^{-1}$ and $\mathrm{H}^{+}$ions during the leaching test. This is because Cs becomes a part of the network modifiers and the XPS spectra in Fig. 12B shows that valence state of Cs was +1 , and present in oxide form in the glass matrix. However, more research could be conducted in the future to estimate polymerisation state of ABG and the distance (in $\AA$ ) of Cs-Si bonds in the glass, using X-ray absorption near K-edge and extended Xray absorption fine structure spectroscopy [28].

A previous study showed that the activation energy of aluminaborosilicate waste glass was $56.0 \pm 4 \mathrm{~kJ} / \mathrm{mol}$ and for British Magnox waste glass was between 56.0 and $64.0 \mathrm{~kJ} / \mathrm{mol}$ [25]. These values were based on boron dissolution rate in de-ionised water. Since 
the activation energy is the energy that must be overcome in order to initiate the dissolution of glass precursors in water, and the activation energy for $A B G$ is equal to or slightly higher than activation energy for British Magnox waste glass, we may suggest that $A B G$ have at least the same or higher chemical durability than British Magnox waste glass.

\section{Conclusion}

The study examined the corrosion of GGC and ABG matrices and assessed their performance as waste forms in order to justify their deep geological disposal in a repository. TRSIO particles, doped with cesium oxide, were encapsulated in ABG and GGC matrices. The weight fractions of Cesium in ABG and GGC and their volatilisation during hot isostatic sintering were taken into the account and were estimated using X-ray computed tomography. The loss values of Cs from the matrix, during the leach test, were impossible to estimate due to the low resolution $(6.5 \mu \mathrm{m})$ which was inappropriate for detection of small loss quantities. The chemical durability of $A B G$ and GGC were directly related to the temperature of the leach tests and the chemical bonding in the matrix. The leach tests of both ABG and GGC matrices were performed for 28 days at temperatures ranging between $298 \mathrm{~K}$ and $363 \mathrm{~K}$, using Cs as a tracer. Cesium was successfully trapped in the ABG network, which resulted in an activation energy $(65.6 \mathrm{~kJ} / \mathrm{mol})$ near to that obtained for boron $(64.3 \mathrm{~kJ} / \mathrm{mol})$ and slightly lower than that for silica $(69.6 \mathrm{~kJ} / \mathrm{mol})$. X-ray diffraction revealed the growth of Crystobalite $\mathrm{SiO}_{2}$ on $\mathrm{ABG}$ surface as a protective layer during the leaching. The existence of the nano-pores in GGC facilitates migration of Cs to the water and makes the matrix unfavourable for immobilisation of radioactive waste, in contrast to ABG.

\section{Acknowledgements}

We wish to thank various people for their contribution to this project; the staff of the workshop at Material Science Centre for manufacturing graphite dies and to the EPSRC grants holders that funded the X-ray tomography work (EP/F007906/1). Special thanks should be given to The Board of Directors for The Common Wealth Academic Trust. The authors also acknowledge the support of Prof. Joseph Sommers from The Institute for Transuranium Elements/ Germany, for supplying TRISO particles.

\section{References}

[1] J. Fachinger, Inventory of reactor graphite and treatment for disposal, in: RADWAP, Würzburg, Germany, 27-31 October 2008,
[2] F. Guittonneau, A. Abdelouas, B. Grambow, B. Grambow, M. Dialinas, F. Celier, New method for HTR fuel waste management, in: 4th International Topical Meeting on High Temperature Reactor Technology, Washington, USA, 2008.

[3] A. Abdelouas, S. Noirault, B. Grambow, Journal of Nuclear Materials 358 (2006) $1-9$.

[4] F. Guittonneau, A. Abdelouas, B. Grambow, M. Dialin, New method for HTR fuel waste management, in: 4th International Topical Meeting on High Temperature Reactor Technology, Washington, USA, 2008

[5] J. Fachinger, K.H. Grosse, R. Seeman, M. Hrovat, Impermeable graphite: a new development for embedding radioactive waste and an alternative option of managing irradiated graphite, in: Radioactive Waste Management Symposia, Conference Proceeding, Phoenix/Arizona, Paper 10027, USA, 2010.

[6] N.H. Hamodi, T.J. Abram, International Journal of Applied Glass Science 2 (4) (2011) 20-24.

[7] L.A. Yurkov, B.I. Polyyak, T.V. Murahver, Journal of Material Science Letters 10 (1991) 1342-1343.

[8] L. Jun, L. Ruiying, C. Yaping, X. Qiao, L. Chen, C. Jiwei, Journal of Surface Science 255 (5) (2008) 1967-1974.

[9] N.H. Hamodi, T. Lowe, T.J. Abram, Journal of Applied Glass Science 3 (2) (2012) $1-9$.

[10] W.J. Gary, Radioactive Waste Management and The Nuclear Fuel Cycle 3 (2) (1982) 137-149.

[11] T.A. Abrajano, J. K bates, A.B. Woodland, J.P. Bradley, W.L. Bourcier, Journal of Clay and Clay Minerals 38 (1990) 83-105.

[12] Y. Inagaki, H. Furuya, K. Idemitsu, S. Yonezawa, Journal of Nuclear Material 208 (1-2) (1994) 27-34.

[13] D. D Walker, J.R. Wiley, M.D. Dukes, J.H. LeRoy, Journal of Nuclear and Chemical Waste Management 3 (1982) 91-94.

[14] C. Jantzen, K. Brown, J. Pickett, International Journal of Applied Glass Science 1 (1) (2010) 38-62.

[15] E. López Honorato, P.J. Meadows, J. Tan, P. Xiao, Journal of Material Research 23 (2008) 6.

[16] Mei-Hsin Chen, Chih-I Wu, Journal of Applied Physics 104 (11) (2008) 1063 1067.

[17] T. Briere, A. Sommer, Journal of Applied Physics 48 (1977) 3547.

[18] J. Juoi, M.I. Ojovan, Characterisation and durability of glass composite waste forms immobilising spent clinoptilolite, in: Waste Management Conference Proceeding, Tucson, AZ, USA, 2007.

[19] D. Banerjee, V. Sudarsan, Annie Joseph, R. Mishra, P. Kishen Wattal, D. Das, Journal of American Ceramic Society 93 (10) (2010) 3252-3258.

[20] W. Bumronngjaroen, I. Muller, J. Schweitzer, R.A. Livingston, Application of glass corrosion test to the reactivity of fly ash, in: World of Coal Ash, Northern Kentucky, USA, 2007.

[21] C.L. Crawford, N.E. Bibler, Effect of Temperature and Radiation on the Nuclear Waste Glass Product Consistency Leach Test, Report WSRC_MS-92-505, Aiken, 1992.

[22] X. Feng, J.K. Bates, C.R. Bradley, E.C. Buck, Does fully radioactive glass behave differently than simulated waste glass, in: Material Research Society Symposia Proceeding 294, 1993, pp. 207-217.

[23] R. Bruckner, H.U. Chun, H. Chun, H. Goretzki, M. Sammet, Journal of NonCrystalline Materials 42 (1980) 49-60.

[24] S. Fairchild, T. Back, P. Murray, M. Cahay, D. Shiffler, Journal of Vacuum Science and Technology A29 (2011) 031402.

[25] E. Pierce, E. Rogdriguez, L.J. Calligan, W. Shaw, B. McGrail, Journal of Applied Geochemistry 23 (2008) 2559-2573.

[26] M.I. Ojovan, R.J. Hand, N.V. Ojovan, W.E. Lee, Journal of Nuclear Material 340 (2005) $12-24$.

[27] W.C.A.N. Ceelen, J.P. Jacobs, H.H. Brongersma, Journal of Surface and Interface Analysis 23 (1995) 712-716.

[28] M. Le Grand, A.Y. Ramos, G. Calas, L. Galoisy, D. Ghaleb, F. Pacaud, Journal of Material Research 15 (9) (2000) 2015-2019. 